\title{
EFEITO DE DIFERENTES ADITIVOS SOBRE A QUALIDADE FERMENTATIVA DA SILAGEM DE RESÍDUO DE MARACUJÁ AMARELO ${ }^{1}$
}

\author{
Effects of different additives on the quality of yellow passion fruit residue silage
}

\author{
Arnaldo Prata Neiva Júnior ${ }^{2}$, José Cleto da Silva Filho³, Igor Maximiliano Eustáquio V. Von Tiesenhausen ${ }^{4}$ \\ Rilke Tadeu Fonseca de Freitas ${ }^{3}$, Cristóvão Colombo de Carvalho Couto Filho ${ }^{5}$, Denismar Nogueira ${ }^{6}$
}

\begin{abstract}
RESUMO
Com o objetivo de estudar o efeito da inclusão de resíduos em diferentes níveis, sobre a qualidade fermentativa da silagem do resíduo de maracujá amarelo, foi conduzido este estudo. Os resíduos foram ensilados em silos experimentais de PVC, adaptados com válvula tipo Bünsen e com capacidade para aproximadamente $3 \mathrm{~kg}$ cada. Os tratamentos constituíramse de três aditivos (bagaço de cana (BC), casca de café (CC) e sabugo de milho (SM)), em quatro níveis (10, 15, 20 e 25\%) mais um tratamento testemunha, sem aditivos. O delineamento experimental utilizado foi o inteiramente casualizado, constituindo um esquema fatorial com tratamento adicional $[(3 \mathrm{x} 4)+1]$ com 4 repetições. As silagens em que se adicionou $\mathrm{BC}$ e as silagens com $100 \%$ de resíduo do fruto de maracujá apresentaram teor de MS inferior aos recomendados para uma silagem. $\mathrm{O}$ aditivo $\mathrm{CC}$ foi o único que aumentou o teor protéico das silagens. Todas as silagens apresentaram valores de $\mathrm{pH}$ e $\mathrm{N}_{-} \mathrm{NH}_{3}(\% \mathrm{~N}$ total) de acordo com os padrões que caracterizam uma fermentação adequada, sendo os valores de $\mathrm{pH}$ inferiores a 4,2 e $\mathrm{N}_{-\mathrm{NH}_{3}}(\% \mathrm{~N}$ total) menores que $10 \%$. As silagens com $100 \%$ de resíduo do fruto de maracujá, e as com BC ou $\mathrm{CC}$ adicionados nos diferentes níveis, apresentaram valores de MS, $\mathrm{PB}, \mathrm{pH}$ e $\mathrm{N}-\mathrm{NH}_{3}$ que caracterizam uma silagem de adequada qualidade fermentativa.
\end{abstract}

Termos para indexação: Resíduo de maracujá, alimento alternativo, aditivo, alimentação de ruminante.

\begin{abstract}
Aiming to evaluate the effect the addition of residues in different levels on the quality of passion fruit residue silage, this study was undertaken. The residues were ensiled in experimental PVC silos, fitted with Bunsen-type valves with a capacity of about $3 \mathrm{~kg}$ each. The treatments consisted of three additives (sugar-cane bagasse (SCB), coffee hulls (CH) and corn cob (CC)) at four levels (10, 15,20 and $25 \%$ ) plus a control treatment without additive. The experimental design used was the completely randomized, in a factorial scheme with an additional treatment $[(3 \times 4)+1]$ with four replicates. The silages in which SCB was added and the silages with $100 \%$ of yellow passion fruit residue had a less DM content to the recommended for a good silage. The additive $\mathrm{CH}$ was the only that increased the protein content of the silages. All the silages showed values of $\mathrm{pH}$ and $\mathrm{N}-\mathrm{NH} 3$ (\% total $\mathrm{N}$ ) according to the standards which characterize a good fermentation process. The silages with $100 \%$ of passion fruit residue and with SCB or with CC added at the different levels, showed good values of $\mathrm{DM}, \mathrm{CP}, \mathrm{pH}$ and $\mathrm{N}-\mathrm{NH}_{3}$, indicating to be an alternative in ruminant feeding in regions where passion fruit by-product is available.
\end{abstract}

Index terms: Passion fruit, by-products, additive, ruminant feeding, sugar-cane bagasse.

(Recebido em 3 de março de 2005 e aprovado em 27 de julho de 2006)

\section{INTRODUÇÃo}

O processamento industrial de produtos agrícolas no Brasil, para a extração de sucos, polpas e óleos, gera uma grande quantidade de subprodutos, constituídos principalmente por sementes, cascas e polpa. O beneficiamento do maracujá, por sua vez, produz uma quantidade de resíduos que corresponde, aproximadamente, de 65 a $70 \%$ do total da fruta. O Brasil é o maior produtor de maracujá amarelo do mundo. Segundo o IBGE (2004), a produção dessa fruta no ano de 2002 foi de aproximadamente 480.000 toneladas.

Em virtude do Brasil ser um país marcado pela estacionalidade da produção de forragens, fator que constitui o principal entrave na exploração pecuária nacional, busca-se, através de técnicas de conservação de alimento, a obtenção de índices produtivos satisfatórios. Nesse contexto, é indiscutível o papel da silagem como

\footnotetext{
${ }^{1}$ Parte da dissertação de mestrado apresentada à Universidade Federal de Lavras /UFLA - Cx. P. 3037 - 37200-000 - Lavras/MG, pelo primeiro autor ${ }^{2}$ Doutorando em Zootecnia, Professor - Centro de Educação Tecnológica de Rio Pomba/CEFET - Rua Doutor José Sebastião da Paixão, s/n - $36180-000$ Rio Pomba, MG - apnjr@hotmail.com

${ }^{3}$ Doutor em Ciências/Zootecnia, Professor - Departamento de Zootecnia/DZO - Universidade Federal de Lavras/UFLA - Cx. P. 3037 - $37200-000$ Lavras, MG - cleto@ufla.br; rilke@ufla.br

${ }^{4}$ Mestre em Zootecnia, Professor - Departamento de Zootecnia/DZO - Universidade Federal de Lavras/UFLA - Cx. P. 3037 - $37200-000$ - Lavras, MG. ${ }^{5}$ Mestre em Zootecnia, Fiscal Agropecuário - Agência de Defesa Agropecuária do Maranhão - Rua Manoel Gonçalves, 710 , Centro - 65600-110 Caxias, MA - coutofil@yahoo.com.br

${ }^{6}$ Doutorando em Estatística Experimental, Professor - Faculdade de Medicina e Ciências Agrárias - Universidade José do Rosário Vellano - Campus Universitário - 37130-000 - Alfenas, MG - denisnog@ufla.br
} 
volumoso suplementar em períodos de escassez de forragem.

Subprodutos agroindustriais representam fontes valiosas de proteína, energia e fibra para a indústria de produção animal (NRC, 1989). Tradicionalmente, os subprodutos têm sido utilizados como suplementos energéticos e, ou, protéicos, embora o valor desses alimentos como fonte de fibra venha sendo pesquisado recentemente (ALLEN \& GRANT, 2000; PEREIRA et al., 1999; SLATER et al., 2000).

A ensilagem de resíduos provenientes da agroindústria frutícola vem surgindo como uma alternativa às culturas tradicionais, tendo como vantagem um baixo custo de aquisição do material a ser ensilado. Além disso, o aproveitamento destes resíduos contribui para minimizar o impacto causado pelo acúmulo destes no meio ambiente.

Algumas limitações podem fazer com que a silagem do resíduo de maracujá tenha uma utilização mais restrita, entre elas a baixa porcentagem de MS, o que prejudica o processo de ensilagem, exigindo a adoção de procedimentos que modifiquem este quadro.

Com o presente trabalho, objetivou-se estudar o efeito da inclusão de bagaço de cana, casca de café e sabugo de milho, em diferentes níveis, sobre a qualidade fermentativa da silagem do resíduo de maracujá.

\section{MATERIAL E MÉTODOS}

O trabalho foi realizado nas dependências do Departamento de Zootecnia da Universidade Federal de Lavras, de julho a setembro de 2003.

O resíduo do processamento do maracujá foi concedido pela empresa Bela Ischia, situada no município de Astolfo Dutra-MG, e os aditivos foram fornecidos por produtores do município de Rio Pomba - MG. O bagaço de cana, obtido em alambique de cachaça, passou por um pré-murchamento e em seguida foi picado em picadeira eletromecânica, antes de ser ensilado. O sabugo de milho também passou por tratamento físico, sendo triturado em triturador de milho. A casca de café e o resíduo de maracujá (casca + sementes) não sofreram nenhum processo de trituração mecânica.

O material foi levado para um galpão onde foi confeccionada a silagem. Para tanto, foram utilizados silos de PVC com diâmetro de $10 \mathrm{~cm}$ e altura de $40 \mathrm{~cm}$, com capacidade para aproximadamente $3,0 \mathrm{~kg}$ de silagem.

Os aditivos e o resíduo de processamento do maracujá foram pesados separadamente e misturados no momento da ensilagem, nos níveis de 0,10, 15, 20 e 25\%, com base na matéria verde. O material foi compactado manualmente nos silos. Finalmente, estes foram fechados com tampa de PVC, dotados de válvula tipo "Bunsen" e vedados com fita isolante.

Após 70 dias os silos foram abertos, sendo desprezadas as porções inicial e final de cada silo. O restante do material foi homogeneizado e amostrado. Em seguida, procedeu-se à pré-secagem do material em estufa de ventilação forçada a $65^{\circ} \mathrm{C}$, por 120 horas. As amostras pré-secas foram moídas em peneira de $1 \mathrm{~mm}$, utilizando-se moinho estacionário e guardadas em recipientes de polietileno. Posteriormente, procedeu-se a determinação dos teores de matéria seca em estufa a $105^{\circ} \mathrm{C}$, proteína bruta $(\mathrm{PB})$ pelo método Kjeldhal e nitrogênio amoniacal segundo a AOAC (1990). A avaliação do $\mathrm{pH}$ foi realizada utilizando-se $10 \mathrm{~g}$ de forragem com $50 \mathrm{~mL}$ de água destilada, pelo método do potenciômetro, conforme citação de Silva (2004).

O delineamento foi inteiramente casualizado, com 4 repetições, sendo os tratamentos arranjados em um esquema fatorial [(3 x 4) +1], constituídos, respectivamente, pelos aditivos bagaço de cana, casca de café e sabugo de milho nos níveis $10,15,20,25 \%$ e um tratamento adicional (testemunha). Os resultados obtidos foram submetidos à análise de variância e de regressão (FERREIRA, 2000). O estudo comparativo das médias dos tratamentos foi realizado pelo teste de Student-Newman-Keuls, a 5\% de probabilidade. Para os fatores níveis de aditivos e desdobramento da interação aditivos x níveis, foi efetuado o estudo de regressão quando ocorreu significância no teste F.

\section{RESULTADOS E DISCUSSÃO}

Os resultados referentes à composição bromatológica do resíduo de maracujá e dos aditivos utilizados estão apresentados na Tabela 1 .

TABELA 1 - Teores de matéria seca (MS) e proteína bruta (PB) na MS do resíduo de maracujá e dos diferentes aditivos utilizados antes da ensilagem.

\begin{tabular}{lcc}
\hline \multicolumn{1}{c}{ Aditivos } & MS $(\boldsymbol{\%})$ & PB $(\boldsymbol{\%})$ \\
\hline Bagaço de cana & 69,15 & 2,63 \\
Casca de café & 89,44 & 10,20 \\
Sabugo de milho & 91,73 & 2,40 \\
Resíduo de & 23,70 & 8,65 \\
maracujá & & \\
\hline
\end{tabular}


Os teores de MS encontrados no bagaço de cana, casca de café e sabugo de milho foram superiores aos valores encontrados por Barcelos (2000) e Evangelista (2001), iguais a $50,6 \%$ e $88,4 \%$, respectivamente, no bagaço de cana e na casca de café; e por Cappelle (2000), 87,5\%, no sabugo de milho.

Quanto ao teor de PB, observou-se, no bagaço de cana, um valor próximo ao encontrado por Evangelista (2001) (2,4\%). O aditivo sabugo de milho apresentou um teor de $\mathrm{PB}$ um pouco mais baixo do que o valor encontrado no bagaço de cana. A casca de café apresentou um teor de PB mais alto que os demais aditivos utilizados e semelhantes aos valores relatados por Barcelos (2000).

A adição dos aditivos no momento da ensilagem do resíduo do fruto de maracujá mostrou-se, em geral, ser uma técnica eficiente em elevar os teores de MS da massa ensilada (Tabela 2). A elevação dos teores de MS é resultado, principalmente, dos altos teores de MS dos aditivos adicionados.

\section{Características das silagens}

As silagens experimentais apresentaram características apropriadas, como odor agradável, coloração amarelada, cheiro característico do fruto, textura firme e ausência de fungos. Notou-se coloração escura nas silagens, onde houve adição de casca de café, fenômeno este mais acentuado na silagem com $75 \%$ de resíduo do fruto de maracujá e $25 \%$ de casca de café.

Os resultados referentes à composição bromatológica e padrão de fermentação das silagens dos diferentes tratamentos estão apresentados nas Tabelas 2 e 3, respectivamente.

\section{Teor de matéria seca (MS) das silagens}

Não foi verificada interação significativa $(\mathrm{P}>0,05)$ entre aditivos e níveis de aditivos. Os aditivos propiciaram o mesmo comportamento, de modo que, com o aumento dos níveis de adição de $10 \%$ para $25 \%$, houve um incremento linear significativo $(\mathrm{P}<0,01)$ dos teores de MS das silagens de $24,20 \%$ para $32,09 \%$.

Os altos teores de matéria seca da casca de café e sabugo de milho aumentaram o teor de matéria seca das silagens, quando estes aditivos foram misturados a essas silagens. Comparando-se as médias dos três aditivos, verificou-se maior valor de MS no sabugo de milho $(32,57 \%)$, seguido da casca de café $(29,44 \%)$ e do bagaço de cana $(22,42 \%)$, tendo os três aditivos diferido entre si $(\mathrm{P}>0,05)$ (Tabela 4).
TABELA 2 - Teores de matéria seca (MS) e de proteína bruta (PB) na MS das silagens dos diferentes tratamentos.

\begin{tabular}{lcr}
\hline \multicolumn{1}{c}{ Trat. } & MS(\%) & PB (\%) \\
\hline $100 \% \mathrm{RM}$ & 23,73 & 11,35 \\
$90 \% \mathrm{RM}+10 \% \mathrm{BC}$ & 19,31 & 9,61 \\
$90 \% \mathrm{RM}+10 \% \mathrm{CC}$ & 24,11 & 11,44 \\
$90 \% \mathrm{RM}+10 \% \mathrm{SM}$ & 28,43 & 7,59 \\
$85 \% \mathrm{RM}+15 \% \mathrm{BC}$ & 21,56 & 9,29 \\
$85 \% \mathrm{RM}+15 \% \mathrm{CC}$ & 28,81 & 11,86 \\
$85 \% \mathrm{RM}+15 \% \mathrm{SM}$ & 31,39 & 7,02 \\
$80 \% \mathrm{RM}+20 \% \mathrm{BC}$ & 22,43 & 8,57 \\
$80 \% \mathrm{RM}+20 \% \mathrm{CC}$ & 30,94 & 12,13 \\
$80 \% \mathrm{RM}+20 \% \mathrm{SM}$ & 34,75 & 6,26 \\
$75 \% \mathrm{RM}+25 \% \mathrm{BC}$ & 26,40 & 8,09 \\
$75 \% \mathrm{RM}+25 \% \mathrm{CC}$ & 33,93 & 12,39 \\
$75 \% \mathrm{RM}+25 \% \mathrm{SM}$ & 35,71 & 6,22 \\
\hline
\end{tabular}

RM: Resíduo de maracujá;

BC: Bagaço de cana;

CC: Casca de café;

SM: Sabugo de milho;

TABELA 3 - Valores de pH e teores de nitrogênio amoniacal como porcentagem do nitrogênio total $\mathrm{N}$ $\mathrm{NH}_{3}(\%$ Ntotal $)$ das silagens dos diferentes tratamentos.

\begin{tabular}{lcc}
\hline \multicolumn{1}{c}{ Trat. } & $\mathbf{p H}$ & $\mathbf{N}-\mathbf{N H}_{\mathbf{3}}(\boldsymbol{\%})$ \\
\hline $100 \% \mathrm{RM}$ & 3,51 & 3,29 \\
$90 \% \mathrm{RM}+10 \% \mathrm{BC}$ & 3,62 & 2,73 \\
$90 \% \mathrm{RM}+10 \% \mathrm{CC}$ & 3,77 & 3,70 \\
$90 \% \mathrm{RM}+10 \% \mathrm{SM}$ & 3,64 & 3,70 \\
$85 \% \mathrm{RM}+15 \% \mathrm{BC}$ & 3,71 & 2,97 \\
$85 \% \mathrm{RM}+15 \% \mathrm{CC}$ & 3,93 & 3,93 \\
$85 \% \mathrm{RM}+15 \% \mathrm{SM}$ & 3,72 & 3,81 \\
$80 \% \mathrm{RM}+20 \% \mathrm{BC}$ & 3,73 & 2,74 \\
$80 \% \mathrm{RM}+20 \% \mathrm{CC}$ & 4,05 & 3,90 \\
$80 \% \mathrm{RM}+20 \% \mathrm{SM}$ & 3,78 & 3,37 \\
$75 \% \mathrm{RM}+25 \% \mathrm{BC}$ & 3,73 & 2,66 \\
$75 \% \mathrm{RM}+25 \% \mathrm{CC}$ & 4,14 & 3,93 \\
$75 \% \mathrm{RM}+25 \% \mathrm{SM}$ & 3,80 & 3,85 \\
\hline
\end{tabular}

RM: Resíduo de maracujá;

BC: Bagaço de cana;

CC: Casca de café;

SM: Sabugo de milho; 
TABELA 4 - Teores de matéria seca (MS) das silagens de resíduo do fruto de maracujá com bagaço de cana, casca de café e sabugo de milho.

\begin{tabular}{lc}
\hline \multicolumn{1}{c}{ Aditivo } & MS (\%) \\
\hline Bagaço de cana & $22,42 \mathrm{a}$ \\
Casca de café & $29,44 \mathrm{~b}$ \\
Sabugo de milho & $32,57 \mathrm{c}$ \\
\hline
\end{tabular}

Médias seguidas por letras diferentes são estatisticamente diferentes, pelo teste SNK, a 5\% de probabilidade.

Todas as silagens em que se adicionou bagaço de cana, bem como a silagem com $100 \%$ de resíduo de maracujá, apresentaram teor de MS inferior aos teores recomendados para uma boa silagem. Muck (1998) cita que o teor de MS da planta é um fator importante no processo de ensilagem e deve situar-se entre de 30 e $35 \%$ para que o alimento seja bem conservado. No geral, a adição de bagaço de cana, casca de café e sabugo de milho aumentou o teor de matéria seca em relação ao resíduo de maracujá puro.

\section{Teor de proteína bruta (PB) das silagens}

Com relação ao teor de $\mathrm{PB}$, verificaram-se diferenças significativas entre os aditivos e seus níveis $(\mathrm{P}<0,01)$, tendo a interação níveis $\mathrm{x}$ aditivos sido significativa $(\mathrm{P}<0,01)$. Nos aditivos bagaço de cana e sabugo de milho, foi observado um decréscimo linear significativo $(\mathrm{P}<0,01)$ no teor de PB de 9,68 para $8,1 \%$ e 7,50 para $6,04 \%$, respectivamente, à medida que se elevaram os níveis de adição de 10 para $25 \%$ (Figura 1). Com a adição de casca de café foi observado um aumento linear significativo $(\mathrm{P}<0,01)$ no teor de $\mathrm{PB}$ de 11,49 para $12,42 \%$, à medida que se elevaram os níveis de adição de 10\% para 25\% (Figura 1). Isto é explicado pelo teor mais elevado de PB da casca de café $(10,20 \%)$ em relação ao sabugo de milho $(2,40 \%)$ e bagaço de cana $(2,63 \%)$.

Observou-se que as silagens de todos os tratamentos em que houve adição do bagaço de cana e casca de café apresentaram teores de proteína bruta acima de $7 \%$, ao contrário das silagens em que $\mathrm{o}$ aditivo utilizado foi o sabugo de milho. No geral, as concentrações de proteína bruta na MS das silagens estudadas neste trabalho estão acima do mínimo exigido nas dietas dos ruminantes, cujo valor é de 7\%, conforme relatado por Church (1988). Este autor salienta, ainda, que esse valor está associado a uma melhor fermentação microbiana efetiva no rúmen dos animais.

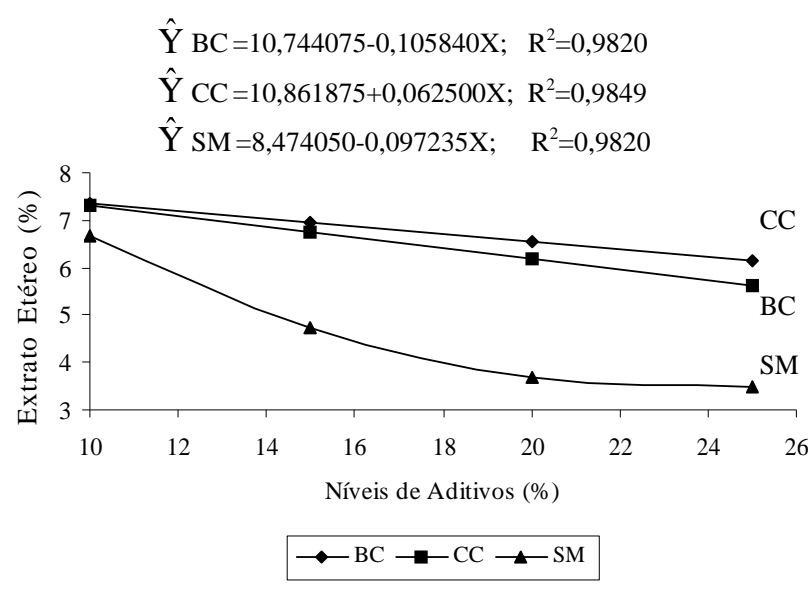

FIGURA 1 - Teores de proteína bruta (PB) das silagens do resíduo do fruto de maracujá em função dos níveis de adição dos aditivos bagaço de cana (BC), casca de café (CC) e sabugo de milho (SM).

\section{Valores de pH e nitrogênio amoniacal das silagens}

Com relação aos valores de $\mathrm{pH}$, verificaram-se diferenças significativas entre os aditivos e níveis $(\mathrm{P}<0,01)$, tendo a interação aditivos $\mathrm{x}$ níveis sido significativa $(\mathrm{P}<0,01)$.

Em relação à qualidade fermentativa das silagens, medida pelos valores de $\mathrm{pH}$, pode-se inferir que tanto a silagem com $100 \%$ de resíduo do fruto de maracujá quanto as com níveis de inclusão de 10, 15, 20 e 25\% dos diferentes aditivos apresentaram padrão de conservação adequado, conforme os relatos de Silveira (1975). Este autor relata que uma silagem de boa qualidade deve apresentar $\mathrm{pH}$ menor ou igual a 4,2 .

Entretanto, segundo Woolford (1972), o valor de $\mathrm{pH}$ não pode ser tomado isoladamente como um bom critério de avaliação das fermentações, pois a inibição de fermentações secundárias depende mais da velocidade de abaixamento da concentração iônica e da umidade do meio do que do $\mathrm{pH}$ final do produto.

Os teores de nitrogênio amoniacal das silagens foram influenciados $(\mathrm{P}<0,01)$ pelos diferentes aditivos.

Comparando-se as médias dos três aditivos, verificou-se menor valor de nitrogênio amoniacal nas silagens com bagaço de cana $(2,78 \%)$, seguido pelas silagens com sabugo de milho $(3,68 \%)$ e pelas silagens com casca de café $(3,86 \%)$, sendo que as duas últimas não diferiram entre si $(\mathrm{P}>0,05)$ (Tabela 5). 
TABELA 5 - Teores de nitrogênio amoniacal como porcentagem do nitrogênio total $\left[\mathrm{N}-\mathrm{NH}_{3}(\% \mathrm{~N}\right.$ total $\left.)\right]$ das silagens de resíduo do fruto de maracujá com bagaço de cana, casca de café e sabugo de milho.

\begin{tabular}{lc}
\hline Aditivo & {$\left[\mathbf{N}-\mathbf{N H}_{\mathbf{3}}(\% \mathbf{N}\right.$ total $\left.)\right]$} \\
\hline Bagaço de cana & $2,78 \mathrm{~b}$ \\
Sabugo de milho & $3,68 \mathrm{a}$ \\
Casca de café & $3,86 \mathrm{a}$ \\
\hline
\end{tabular}

Médias seguidas por mesma letra são estatisticamente iguais, pelo teste SNK, a 5\% de probabilidade.

No geral, as adições de bagaço de cana, casca de café e sabugo de milho à silagem de resíduo do fruto de maracujá provocaram algumas variações no teor de $\mathrm{N}-\mathrm{NH}_{3}$ (\% $\mathrm{N}$ total); no entanto, todas as silagens apresentaram baixos teores de nitrogênio amoniacal, sendo classificadas como de boa qualidade. Uma silagem bem preservada deve apresentar teores de $\mathrm{N}_{-} \mathrm{NH}_{3}$ (\% $\mathrm{N}$ total) menores que $10 \%$ (McDonald, 1981). Analisando-se os dados da Tabela 1, verifica-se que todas as silagens estão dentro de uma faixa considerada desejável de $\mathrm{N}-\mathrm{NH}_{3}(\% \mathrm{~N}$ total $)$, podendo-se concluir que, durante o processo fermentativo, houve a preservação das proteínas e compostos nitrogenados ou seja, não houve degradação ao ponto de reduzir o conteúdo de $\mathrm{N}$ das silagens.

\section{CONCLUSÕES}

$\mathrm{O}$ aditivo casca de café foi o único que aumentou significativamente o teor protéico das silagens.

Quanto à qualidade de fermentação, todas as silagens em estudo apresentaram valores de $\mathrm{pH}$ e de $\mathrm{N}$ $\mathrm{NH}_{3}$ (\% $\mathrm{N}$ total), de acordo com os padrões que caracterizam uma boa fermentação.

As silagens com $100 \%$ de resíduo do fruto de maracujá, e as com BC ou CC adicionados nos diferentes níveis, apresentaram valores de $\mathrm{MS}, \mathrm{PB}, \mathrm{pH}$ e N-NH $\mathrm{N}_{3}$ que caracterizam uma silagem de boa qualidade.

\section{REFERÊNCIAS BIBLIOGRÁFICAS}

ALLEN, D. M.; GRANT, R. J. Interactions between forage and wet corn gluten feed as sources of fiber in diets for lactating dairy cows. Journal of Dairy Science, Champaign, v. 83, n. 2, p. 322-331, Feb. 2000.

ASSOCIATION OF OFFICIAL AGRICULTURAL CHEMISTS. Official methods of analysis. 15. ed. Virginia, 1990. v. 1.
BARCELOS, A. F. Parâmetros bromatológicos, frações de carboidratos e degradabilidade in vitro da casca e da polpa de café (Coffea arábica L.). 2000. 96 p. Tese (Doutorado em Nutrição de Ruminantes) - Universidade Federal de Lavras, Lavras, 2000.

CAPPELLE, E. R. Tabelas de composição dos alimentos, estimativa do valor energético e predição do consumo e do ganho de peso de bovinos. 2000. $369 \mathrm{f}$. Tese (Doutorado em Zootecnia) - Universidade Federal de Viçosa, Viçosa, 2000.

CHURCH, D. C. The ruminant animal digestive physiology and nutrition. New Jersey: Prentice Hall, 1988. 564 p.

EVANGELISTA, A. R. Aproveitamento de resíduos da fabricação da aguardente. In: CARDOSO, M. das G. (Ed.). Produção de aguardente de cana-de-açúcar. Lavras: UFLA, 2001. p. 128-151.

FERREIRA, D. F. Análises estatísticas por meio do Sisvar para Windows versão 4.0. In: REUNIÃO ANUAL DA REGIÃO BRASILEIRA DA SOCIEDADE INTERNACIONAL DE BIOMETRIA, 45., 2000, São Carlos. Anais... São Carlos: UFSCar, 2000. p. 255-258.

INSTITUTO BRASILEIRO DE GEOGRAFIA E ESTATÍSTICA. IBGE. Disponível em: <http:// www.ibge.gov.br>. Acesso em: 9 nov. 2004.

McDONALD, P. The Biochemistry of silage. New York: J. Wiley, 1981. $207 \mathrm{p}$.

MUCK, R. Factores influencing silage quality and their implications for management. Journal of Dairy Science, Champaing, v. 71, n. 11, p. 2992-3002, Nov. 1998.

NATIONAL RESEARCH COUNCIL. Nutrient requirements of domestic animals: nutrient requirements of dairy cattle. 6. ed. rev. Washington, 1989. 157 p.

PEREIRA, M. N.; GARETT, E. F.; OETZEL, G. R.; ARMENTANO, L. Partial replacement of forage with nonforage fiber sources in lactating cow diets: I. performance and health. Journal of Dairy Science, Champaign, v. 82, n. 12, p. 2716-2730, Dec. 1999.

SILVA, D. J. Análise de alimentos: métodos químicos e biológicos. 3. ed. Viçosa: UFV, 2004. 235 p. 
SILVEIRA, A. C. Técnicas para produção de silagens. neutral detergent fiber on performance by dairy cows. In: SIMPÓSIO SOBRE MANEJO DE PASTAGEM, 2., Journal of Dairy Science, Champaign, v. 83, n. 2, p. 3131975, Piracicaba. Anais... Piracicaba: ESALQ, 1975. p. $\quad$ 321, Feb. 2000. 156-180.

SLATER, A. L.; EASTRIDGE, M. L.; FIRKINS, J. L.; WOOLFORD, M. K. Some aspects of the microbiology BIDINGER, L. J. Effect of starch source and level of forage and biochemistry of silage making. Herbage Abstracts, Wallingford, v. 42, n. 2, p. 105-111, June 1972. 